\title{
A brief discussion on the strategies of deep learning in English for Higher Vocational Students
}

\author{
Yu'er Liu \\ Jiangxi Vocational College of Ahead Software, China
}

Keywords: deep learning, Higher Vocational Students, English learning

\begin{abstract}
Based on the concept of deep learning, this paper analyzes the present situation of English learning in Jiangxi Vocational College of Ahead Software, and puts forward the strategies to promote students' deep learning in English,. And moreover: establishing learning goals, stimulating students' learning potential, motivating students' learning motivation, clearly setting up future careers, and creating real situations as far as possible. To promote students' deep learning in classroom, and to promote students' deep learning combined with process evaluation.
\end{abstract}

\section{Background}

With the development of the times, deep learning has become the goal pursued by teachers in teaching and students in learning. The teaching requirements of Higher Vocational Education English course revised by the Ministry of education stipulates that the teaching goal of Higher Vocational English course is not only to help students to make good language foundation, but also to cultivate students' skills in practical application language, especially the ability to deal with future career related business in English. It aims at training students' professionalism, practicality and comprehensive ability. Therefore, it is not only in line with the current practical needs, but also the starting point and destination of Higher Vocational English teaching. Then learners should actively understand knowledge, explore meaning and flexibly use knowledge to solve practical problems for the purpose of deep learning.

\section{Deep learning}

Ference Marton and Roger Saljo, two American scholars first put forward the concept of deep learning and shallow learning in 1976. It is different from the surface learning which is the passive and the mechanical learning way and leaners do not put knowledge into practice. Deep learning usually refers to an autonomous learning under the needs of the learners. In the process of learning, students are emphasized, the learners combine the old and new knowledge, and understand the knowledge. And learners practice construction, criticism and reflection, in order to better transfer the knowledge learned and flexibly apply it to the solution of practical problems. (Wang Yonghua, 2013)

\section{The present situation of English learning for Higher Vocational Students}

Through the investigation and analysis of the students' English learning situation in Jiangxi Pioneer Software Vocational and Technical College, the following problems are found:

\subsection{The mastery degree of knowledge they've learned is low}

The structure of source of students in Jiangxi Vocational College of Ahead Software is complex, mainly composed of general high school students, secondary vocational school students and single enrolment students. The precise reason is that students' source has diversified trends. The English base is uneven, and their enrollment grades are low, especially in the English subject, a large part of the students' English basic knowledge and language ability is not good. Moreover, the learning attitude of the middle school is not correct, and during the higher vocational stage they faces the 
unified learning materials and learning tasks, as well as the same evaluation methods, resulting in their lack of confidence in English learning, and the frustration of their enthusiasm and initiative. And then form a passive and passive attitude in acceptance of knowledge.

\subsection{Lack of learning motivation and unclear future career orientation.}

Actually, the students' frustration caused by the failure of the college entrance examination, the incorrect way of learning, the poor learning interest of the students, which results the lack of internal learning motivation. through my teaching experience for several years and interviews with students, I found that most of the students think there is no need to apply English to their future job, and the students' attitude and enthusiasm for learning English will be discounted, which directly affects the learning enthusiasm of the students. Thus the students' learning motivation which motivated by the external environment is less and less. This will cause some students only to learn some words and sentences in class, or to cope with the passive mechanical test, which stay in surface learning, or even give up English learning.

\subsection{Shortcomings in English Classroom Teaching}

Although English teaching in higher vocational colleges has been reformed recently, the traditional teacher-centered teaching still dominates and students are still in a passive position. In the traditional English class, teachers teach important English vocabulary, grammar, and sentences. The students who learn seriously can follow the teacher's rhythm and grasp the content according to the teaching requirements. But even if the students have mastered the language knowledge, they keep only mechanical memory and are in the surface learning. Furthermore, at present, the English class in higher vocational college belongs to the big class teaching, the students' language practice is less and the language ability is limited, most of the students can not transform the language knowledge into the actual use of language, and the real transfer is applied to practice to achieve deep learning.

\subsection{Curriculum evaluation exists defects}

At present, we adopt formative assessment about the evaluation method of English Curriculum in our college. It is composed of students' usual performance and final examination results. The average score accounts for $30 \%$, and the final grade account for $70 \%$. The usual grades consist of three parts: attendance rate, class performance and homework results. Although this evaluation method revolves the learning process, the subject of evaluation, the content of evaluation and the method of evaluation, it only evaluates the teachers' knowledge teaching objectives and the consistency of the students' knowledge effect. But it neglects the students' logical thinking ability in the process of learning, the ability to analyze and solve the problems, the ability to use learning strategies, the ability of knowledge construction and innovation. Finally curriculum evaluation can not really play its role in promoting students' deep learning.

\section{Strategies English deep learning for Higher Vocational Students}

Prof. Li Jiahou thought deep learning happens on the bases of understanding and criticism. In the process learners construct knowledge between the knowledge they will learn and the knowledge they've learned, and transfer knowledge to the new situation.(He Ling, Li Jiahou 2005) The goal of Higher Vocational English teaching is to cultivate students' practical use of language ability. Only after mastering the learned knowledge and applying the basic knowledge of English in the future career or work life, can we achieve real deep learning. In view of the present situation of vocational college students' English learning, the following English learning strategies are put forward:

\subsection{Establish learning goals and stimulate students' learning potential}

Although most students are enrolled in low grades, especially in the English subject, but the students' learning potential is unlimited, and the teachers have the responsibility to exploit and stimulate the students' potential. First, move them in the emotion, give them more attention, treat all 
the students equally, dig out their advantages, and give them the proper praise. So that they can be confident in English learning. Second, guide students to set up new learning goals and let them understand the importance of English in their future career. Under the background of globalization, many industries need to use English as a language tool. Learning English well can help them to find ideal jobs in the future. Thirdly, improve the English pronunciation ability of poor students. Through years of my teaching experience, it has been found that the primary cause of their poor English is their poor pronunciation , which leads to a series of chain reactions in English learning disabilities. If they improve their English pronunciation, they will achieve self-confidence in English learning and get rid of the embarrassment that they dare not read in English learning

\subsection{Motivating students' learning motivation and clearly positioning future careers}

Although the students' English foundation is poor, each student has chosen the specialty of their own interest after the students enter the higher vocational school. Their learning is no longer in the passive state as the basic education stage, and the teachers must seize this characteristic and stimulate students' intrinsic motivation. Because deep learning is to emphasize the intrinsic motivation, which is the premise of students' autonomous learning. This affects the learning effect of learners to a large extent. We can make use of students' motivation to cultivate students' motivation to study English, because it is one of the essential qualities for higher vocational students to have a foothold in a job with more practical and high job skills in the future. So it will inevitably promote the students to acquire more details of the learner's own professional knowledge and understand professional dynamics by using the English language tool, which can be more accurate and clearer positioning of their own major, so that the learners competition to seize the opportunity in the future job.

\subsection{Try to create real situations to promote students' deep learning in class}

According to the talent training objective of higher vocational college, we chose the English textbook "New Concept Professional English". For example, Unit1 Job application, interview tips. First, we give students tips of the Do 's and Don' ts in the job interview and the questions often asked in the interview, for example, a. Tell us about yourself. b. Why should I hire you? c. Why do you want this job? d. What are your strengths and weaknesses? e. What's your career plan? $\mathrm{f}$. What do you know about us? and so on. In order to make students understand the basic knowledge points that should be done in the interview and should not be done in the interview and the common problems in the interview. The learners should take it down. After the students have mastered the relevant knowledge of the interview, in order to make the students understand the learning situation in depth, the teacher invites some students and teachers to be interviewers, and create a real interview scene for the students. Thus students can further apply the interview knowledge to the interview. We should guide students to actively experience what they have learned, and finally establish connection with the post interview situation and achieve the purpose of learning transfer.

\subsection{Combining process evaluation to promote students' deep learning}

Because of the complex structure of sources of higher vocational college students, the students' English foundation is poor. If only the formative evaluation method is adopted, the purpose of students' English learning is coping with the exam, only get 60 points in final exam. Students' attitude is bad. And most of the students give up their class performance grade in class. This formative evaluation can't monitor the performance of students' learning process, nor can it achieve the effect of deep learning. We appropriately introduce the form of process evaluation. Process evaluation advocates trinity evaluation which includes learning motivation, attitude, process and effect. We can take advantage of the advantage of the higher vocational students' interest in electronic products, combine the contents of the unit, select the relevant English sound soundtrack, and send the task through the Wechat group or QQ group. Then, teacher ask each student to record a piece of voice and submit to the Wechat group in the form of homework, and the students can carry on the mutual evaluation between students and students and point out the advantages and disadvantages. At last, the teacher gave review once a week and show the outstanding works to all 
students ; For the poor students, the teacher gave the corresponding positive evaluation to their study attitude and gave them guidance and encouragement. Teacher gave them the grade for each work, which will be added in the final assessment. In this way, students can understand, apply and transfer knowledge through self evaluation and mutual evaluation, and finally achieve the effect of deep learning.

\section{References}

[1] The Practice and Research of Blended Learning Under the Guidance of Deep Learning Theory. [J]Wang Yonghua. Distance Education in China.2013(7):73-77

[2]Promoting Students’ Deep Learning[J].He Ling,Li Jiahou. Modern Teaching. 2005(05):29-30

[3]Reflection on English teaching models from the perspective of deep learning [J]. Wenjing Fan. Journal of Shijiazhuang University of Applied Technology. 2018(06).

[4] Research on Deep Learning based on the platform of Moodle [J]. Jing Hongna, Chen Lin\&Zhao Xueping. Journal of Distance Education. 2011(03).

[5] Exploration on English Deep Learning Strategies in Blended Learning Mode[J]. Li Ning, Wei Yuying. Journal of North China University of Science and Technology (Social Science Edition). 2018(03)

[6] Analysis of College Students' Deep Learning in English [J].Zou Xiaoyan. Heilongjiang Researches on Higher Education. 2012(12) 